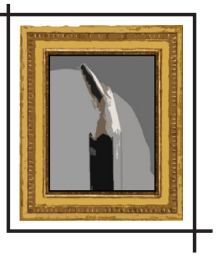

\title{
DIVERSIDADE CULTURAL E O CONTEÚDO DE CIÊNCIAS: UMA TENSÃO NA PROPOSTA CURRICULAR DA EJA
}

\author{
Nedir Soares*
}

Resumo: Este artigo faz uma discussão a partir de uma análise da proposta curricular para ensino de ciências na EJA, elaborada pela Coordenação Geral de Educação de Jovens e Adultos (COEJA). Discutimos como o documento trata a tensão entre os conteúdos de ciências e a atenção à diversidade cultural em sua proposta. Para isso, elaborou-se um questionário, e tanto as perguntas quanto as respostas foram colocadas em dois quadros. No primeiro quadro, temos a apresentação dos conteúdos e, no segundo, o tratamento dado à diversidade cultural. Concluimos que as orientações feitas pela proposta curricular poderão ajudar o professor a escolher os conteúdos mais adequados aos educandos. Observamos que a escolha desses temas poderá acolher a diversidade cultural, contudo o foco apenas no atendimento à diversidade desses educandos e na formação para a cidadania, em detrimento dos conhecimentos científicos acumulados, poderá reduzir as possibilidades de eles ampliarem seus conhecimentos, acentuando ainda mais as desigualdades.

Palavras-chave: Proposta curricular. Educação de Jovens e Adultos. Diversidade cultural. Conteúdos de ciências. Formação para a cidadania.

\section{INTRODUÇÃO}

As culturas indígena, africana, ocidental e cristã forjaram a cultura brasileira, e grupos representantes dessas culturas coexistem em diferentes locais do território brasileiro. Elaborar um currículo que contemple toda essa diversidade cultural e ainda o conhecimento acumulado pela humanidade constitui-se num grande desafio.

A escolha dos conteúdos e o acolhimento da diversidade cultural de maneira que as minorias culturais, religiosas ou raciais se sintam representadas no processo educativo influenciam diretamente o ensino, pois, conforme Jean Claude Forquin (1993), é necessário haver um reconhecimento daquilo que está sendo ensinado tanto por parte dos professores quanto por parte daqueles que aprendem. Sem esse reconhecimento, poderá haver uma resistência

\footnotetext{
* Mestrado em Educação com ênfase em Ensino de Ciências e Matemática pela Universidade de São Paulo (USP). Membro do Grupo de Estudos e Pesquisas em Ensino de Biologia (GEPEB) da Universidade de São Paulo. E-mail: nedir.soares@usp.br
} 
em relação à validade dos conteúdos transmitidos pela escola. Entretanto, é necessário possibilitar o desenvolvimento dos educandos, colocando-os em contato com conhecimentos diferentes dos vivenciados no cotidiano de sua cultura.

0 conhecimento transmitido pela escola amplia o conhecimento vindo do dia a dia dos educandos. Os conhecimentos usados no cotidiano são transmitidos dentro de pequenos grupos, como família, comunidade, igreja, entre outros, e estão presentes em muitas práticas realizadas por diferentes culturas. 0 conhecimento chamado de poderoso por Michael Young (2013) difere dessa forma de conhecimento, o que não significa que ele tenha menor valor, mas pode e deve ser ampliado no ambiente escolar. Segundo Young (2013), o conhecimento poderoso não se restringe apenas às áreas de conhecimento e disciplinas, ele pode ser generalizado e aplicado a outras áreas também, como a ética, a literatura e as artes, entre outras, generalizando comportamentos que melhoram a convivência entre os seres humanos, independentemente de sua crença ou cultura.

Todavia, é necessária a integração das minorias sociais, étnicas e culturais ao processo educativo. Atender a esses grupos implica ter uma educação com currículo multicultural. No entanto, essa questão configura-se como uma tensão para os elaboradores de currículos, pois suscita um questionamento acerca da capacidade de a educação acolher a diversidade cultural e o conhecimento poderoso, como destacou Young (2013).

Para José Gimeno Sacristán (1995, p. 82):

A cultura escolar não poderá, em seus conteúdos e práticas, levar em consideração e fazer com que os membros de uma minoria cultural se sintam acolhidos, se toda a cultura escolar não trata adequadamente o problema mais geral do currículo multicultural, e não poderá chegar a esse se não se discute a questão da diversidade em geral.

A inserção de diferentes aspectos culturais no currículo permite à educação trabalhar o conhecimento poderoso a partir desses aspectos e fazer as generalizações de comportamentos apontadas por Young (2013).

Quando pensamos na Educação de Jovens e Adultos (EJA), percebemos que, nessa modalidade de ensino, há um público que tem participação no processo de tomada de decisão na sociedade. A apropriação do conhecimento acumulado poderá modificar as relações desse educando com o meio em que está inserido, e o contato com a diversidade cultural favorecerá o respeito às diferenças culturais e étnicas.

Neste artigo, analisaremos o currículo da EJA para o ensino de ciências, buscaremos identificar como o currículo para essa disciplina faz a apresentação de seus conteúdos e como é o tratamento conferido à diversidade cultural. Discutir essas características, analisando o currículo da EJA e, especificamente, a disciplina de ciências, mostra-se relevante pelo fato de a EJA ter um público com influência nas tomadas de decisões da sociedade e porque o ensino de ciências pode ser um parceiro que favorece o contato dos educando com os conhecimentos 
científicos, os quais, articulados com os saberes de diferentes culturas e grupos, podem contribuir para a ampliação dos conhecimentos dos educandos, bem como para o convívio mais respeitoso entre as pessoas.

\section{METODOLOGIA UTILIZADA NA ANÁLISE DOCUMENTAL}

Analisaremos a proposta curricular, elaborada pelo Ministério da Educação (MEC) em 2002, para o ensino de ciências da EJA destinado aos alunos que estão no segundo segmento do ensino fundamental. Para analisarmos como o currículo da EJA para o ensino de ciências estruturou-se diante da tensão entre conhecimentos e atenção à diversidade cultural, desenvolvemos um roteiro para análise documental, dividido em dois temas: a apresentação dos conteúdos de ciências e o tratamento conferido à diversidade cultural. Cada tema possui um conjunto de questões que auxiliam na identificação de como ele é abordado pelo documento. Dessa maneira, para o tema apresentação dos conteúdos de ciências, temos as seguintes questões:

- Há destaque para a história da produção do conhecimento em ciências?

- São apresentados os objetivos assumidos para a disciplina de ciências?

- Há temas/eixos destacados para a identificação de indicações de conteúdo específico?

- Há justificativa para a inclusão desses conteúdos na formação escolar?

- É feita a distribuição dos conteúdos no período de tempo (bimestre, ano etc.)?

- Há orientações didáticas? Como elas aparecem?

- São sugeridas formas de avaliação?

Em relação ao tema tratamento conferido à diversidade cultural, foram elaboradas as seguintes questões:

- Há menções ao tema? Como ele é justificado?

- Há alguma parte específica do documento destinado ao tema (partes dentro do documento, no tópico da disciplina ou em um tópico separado)?

- Há referenciais teóricos que embasam essa discussão?

- Há temas/eixos destacados para a identificação de indicações de questões que contemplam a diversidade cultural?

\section{RESULTADOS}

As respostas para as questões levantadas foram colocadas em quadros. 0 Quadro 1 contém as respostas das questões referentes à apresentação do conteúdo. 0 Quadro 2 contém 
as respostas das questões acerca do tratamento dado à diversidade cultural. Em ambos, temos as questões, as respostas sim ou não, representadas pelas letras $S$ e $N$, e as evidências. Colocamos, no campo de evidência, uma breve descrição sobre como é abordada a questão no documento.

Quadro 1 Apresentação dos conteúdos

\begin{tabular}{|c|c|c|}
\hline Questões & $\mathrm{S} / \mathrm{N}$ & Evidência \\
\hline $\begin{array}{l}\text { 1) Há destaque para a história } \\
\text { da produção do conhecimento } \\
\text { de ciências? }\end{array}$ & $S$ & $\begin{array}{l}\text { No início do documento, na página 75, há um texto } \\
\text { com o título "Ciências naturais e tecnologia" que } \\
\text { discorre sobre a produção do conhecimento em } \\
\text { ciências intrincada com o avanço tecnológico e } \\
\text { sua influência na sociedade. Por meio de vários } \\
\text { exemplos, esse texto orienta a discussão do processo } \\
\text { histórico de produção de conhecimento com os } \\
\text { educandos da EJA. } \\
\text { Na página 77, a produção do conhecimento como } \\
\text { atividade humana e histórica é tratada como um } \\
\text { dos objetivos dentro dessa modalidade de ensino. }\end{array}$ \\
\hline $\begin{array}{l}\text { 2) São apresentados os objetivos } \\
\text { assumidos para a disciplina de } \\
\text { ciências? }\end{array}$ & $S$ & $\begin{array}{l}\text { Os objetivos fundamentam-se nos mesmos objetivos } \\
\text { gerais do ensino voltado para crianças e adolescentes, } \\
\text { e a justificativa apresentada pelo documento é que } \\
\text { a formação para a cidadania constitui meta de todos } \\
\text { os segmentos e modalidades da escolaridade. São } \\
\text { apresentados oito objetivos, e cada um deles é } \\
\text { comentado, ressaltando as características dos } \\
\text { estudantes jovens e adultos. }\end{array}$ \\
\hline $\begin{array}{l}\text { 3) Há temas/eixos destacados } \\
\text { para identificação de indicações } \\
\text { de conteúdo específico? }\end{array}$ & $S$ & $\begin{array}{l}\text { O documento apresenta uma organização com o } \\
\text { objetivo de auxiliar o docente na análise e escolha } \\
\text { de conteúdos mais adequados à realidade dos } \\
\text { educandos. Os conteúdos são organizados em cinco } \\
\text { modos distintos e complementares: temas } \\
\text { transversais; critérios para a seleção de conteúdos; } \\
\text { valores e atitudes; organização dos conteúdos em } \\
\text { temas de trabalho; e eixos temáticos. }\end{array}$ \\
\hline
\end{tabular}


Quadro 1 Apresentação dos conteúdos (continuação)

\begin{tabular}{|c|c|c|}
\hline Questões & $S / N$ & Evidência \\
\hline $\begin{array}{l}\text { 4) Há justificativa para a } \\
\text { inclusão desses conteúdos } \\
\text { na formação escolar? }\end{array}$ & $S$ & $\begin{array}{l}\text { Cada modo apresenta uma justificativa demonstrando } \\
\text { sua importância para a formação de jovens e adultos. } \\
0 \text { documento, apesar de fazer várias sugestões de } \\
\text { conteúdos na composição de diferentes temas de } \\
\text { trabalho, dá a possibilidade de inclusão de conteúdos } \\
\text { que não foram contemplados e que podem ser mais } \\
\text { adequados à realidade do educando. }\end{array}$ \\
\hline $\begin{array}{l}\text { 5) É feita a distribuição dos } \\
\text { conteúdos em um periodo de } \\
\text { tempo (bimestre, ano etc.)? }\end{array}$ & N & $\begin{array}{l}\text { O documento não define uma distribuição de } \\
\text { conteúdo em um período de tempo, contudo ressalta } \\
\text { a importância de o educando da EJA entrar em } \\
\text { contato com temas pertencentes aos quatro eixos } \\
\text { temáticos (Terra e Universo; Vida e Ambiente; Ser } \\
\text { Humano e Saúde; Tecnologia e Sociedade) e não } \\
\text { apenas a um ou dois deles no decorrer do curso. }\end{array}$ \\
\hline $\begin{array}{l}\text { 6) Há orientações didáticas? } \\
\text { Como elas aparecem? }\end{array}$ & $S$ & $\begin{array}{l}\text { Na página 102, são apresentadas as orientações } \\
\text { didáticas para diferentes formas de trabalho: } \\
\text { - Como elaborar um planejamento de longo termo? } \\
\text { - Como utilizar o livro didático? } \\
\text { - Como ensinar em classes heterogêneas? } \\
\text { Há ainda subsídios para atividades diversificadas } \\
\text { e sistematização do conhecimento. } \\
\text { Cada um dos títulos é apresentado em diferentes } \\
\text { tópicos, detalhado e exemplificado. } \\
\text { Por exemplo: o item "subsidios para atividades } \\
\text { diversificadas" está dividido em problematização } \\
\text { e debate; situações-problema; atividades } \\
\text { permanentes; produção de textos } \\
\text { informativos; pesquisa escolar (coleta de dados } \\
\text { e informações); consultas e entrevistas; entre outros. }\end{array}$ \\
\hline $\begin{array}{l}\text { 7) São sugeridas formas de } \\
\text { avaliação? }\end{array}$ & $S$ & $\begin{array}{l}\text { São apresentadas, na página 127, várias formas } \\
\text { de avaliação. }\end{array}$ \\
\hline
\end{tabular}

Fonte: Elaborado pelo autor. 
Quadro 2 Tratamento dado à diversidade cultural

\begin{tabular}{|c|c|c|}
\hline Questões & $\mathrm{S} / \mathrm{N}$ & Evidência \\
\hline 1) Há menções ao tema? & $S$ & $\begin{array}{l}\text { A menção direta ao tema é feita nos temas } \\
\text { transversais. }\end{array}$ \\
\hline $\begin{array}{l}\text { 2) É feita alguma justificativa } \\
\text { para menções ao tema? }\end{array}$ & $S$ & $\begin{array}{l}0 \text { documento apresenta algumas justificativas, } \\
\text { como: "a concepção subjacente a este tema é o } \\
\text { reconhecimento da diversidade cultural como } \\
\text { direito dos povos e dos individuos e fator de } \\
\text { fortalecimento da democracia" (BRASIL, 2002, } \\
\text { p. 88). }\end{array}$ \\
\hline $\begin{array}{l}\text { 3) Há alguma parte específica do } \\
\text { documento destinado ao tema } \\
\text { (partes dentro do documento, no } \\
\text { tópico da disciplina ou em tópico } \\
\text { separado)? }\end{array}$ & $S$ & $\begin{array}{l}\text { No documento, há uma parte destinada a temas } \\
\text { transversais, que é subdividida em: meio ambiente; } \\
\text { saúde; orientação sexual; trabalho e consumo; } \\
\text { pluralidade cultural e ética. A parte de pluralidade } \\
\text { cultural trata especificamente da questão da } \\
\text { diversidade cultural e como será abordada a } \\
\text { temática dentro do ensino do ensino de ciências } \\
\text { na EJA. }\end{array}$ \\
\hline $\begin{array}{l}\text { 4) Há referenciais teóricos que } \\
\text { embasam essa discussão? }\end{array}$ & $\mathrm{N}$ & $\begin{array}{l}\text { Não são apontados referenciais teóricos no corpo } \\
\text { do documento. Algumas sugestões são descritas } \\
\text { nas páginas 129, } 130 \text { e } 131 \text { (bibliografia). Nessa } \\
\text { parte, são feitas sugestões sobre obras para } \\
\text { utilização em sala de aula e sites para o professor } \\
\text { ampliar seus conhecimentos. }\end{array}$ \\
\hline $\begin{array}{l}\text { 5) Há temas/eixos destacados } \\
\text { para identificação de indicações } \\
\text { de questões que contemplam a } \\
\text { diversidade cultural? }\end{array}$ & $S$ & $\begin{array}{l}\text { A parte de pluralidade cultural trata } \\
\text { especificamente da questão da diversidade cultural } \\
\text { e da influência desta no ensino de ciências na EJA. }\end{array}$ \\
\hline
\end{tabular}

Fonte: Elaborado pelo autor.

\section{DISCUSSÃO}

Observando os resultados acerca da apresentação dos conteúdos, nota-se que a proposta pretende orientar o professor na escolha de conteúdos que sejam relevantes aos educandos. 0 documento apresenta como justificativa que a EJA não dispõe da mesma quantidade de aulas do ensino fundamental e, além disso, possui um público muito heterogêneo, que volta à escola em busca de maior inserção social e melhor qualificação para o mercado de trabalho. 
Como se sabe, não é possivel ensinar todos os conceitos científicos ("dar tudo") aos alunos. E não apenas porque a EJA não dispõe da mesma quantidade de aulas do Ensino Fundamental voltado para alunos entre 7 e 14 anos - pois também neste é difícil cumprir programas extensos. A impossibilidade advém principalmente de outros fatores, como a permanente ampliação do conhecimento científico e tecnológico, por exemplo (BRASIL, 2002, p. 82).

Embora o documento considere a produção do conhecimento como atividade humana e histórica como um dos objetivos dentro dessa modalidade de ensino. Chama a atenção a preocupação com questões sociais e de cidadania, apontadas nos objetivos do ensino de ciências para EJA, os quais são fundamentados nos mesmos objetivos gerais do ensino voltado para crianças e adolescentes, apresentados nos Parâmetros Curriculares Nacionais de Ciências Naturais, dirigidos aos educandos com idade entre 7 e 14 anos.

Aparentemente, os objetivos expostos no documento remetem ao que Libâneo (2016) chama de currículo de convívio e acolhimento social, que busca colocar os educandos em contato com um tipo de cidadania baseado na solidariedade e na contenção de conflitos sociais.

Nota-se que o documento pretende dar condições ao professor para escolher os temas mais relevantes a partir da realidade dos educandos, relacionando os objetivos das disciplinas e a análise dos conteúdos por meio de elementos que, segundo o documento, ajudarão na escolha dos temas. Essa possibilidade nos remete ao reconhecimento daquilo que está sendo ensinado tanto por parte dos professores quanto por parte daqueles que aprendem, conforme apontado por Forquin (1993).

Embora o documento apresente uma organização com o objetivo de auxiliar o docente na análise e escolha de conteúdos, e oriente o contato com temas pertencentes aos quatro eixos temáticos e não apenas a um ou dois deles, a escolha desses conteúdos precisa ser discutida e avaliada na comunidade escolar, pois corre-se o risco de aumentar ainda mais a desigualdade, assim como pontua Libâneo (2016), ao fazer uma crítica ao currículo de convívio e acolhimento social. Segundo o autor nesse tipo de currículo a escola é usada como parte de uma estratégia para solução de problemas sociais e econômicos que possam vir afetar a ordem social. Um outro aspecto criticado pelo autor é o rateio da responsabilidade da escola pública entre estado, sociedade e as comunidades. Libâneo (2016) chama a atenção para que a escola nesse modelo passe a ser apenas um espaço de acolhimento e integração social, moderadora de conflitos, desenvolvendo muito pouco os conhecimentos e as habilidades para sobrevivência social.

Ainda que a EJA tenha um periodo menor para aprendizagem, é relevante pontuar quais conhecimentos são importantes para os educandos com as características apresentadas anteriormente e em condições de tempo limitado. A escolha de quais conteúdos ensinar, nos remete a discussão acerca dos conhecimentos poderosos apresentados por Young (2013). 0 documento não distribui os conteúdos em períodos (bimestre, semestre, entre 
outros), entretanto orienta a sua distribuição em temas de trabalho. Segundo o documento, os temas reúnem fatos e conceitos científicos e são desenvolvidos concomitantemente com valores, atitudes e procedimentos, podendo contemplar assuntos relativos a mais de um dos eixos temáticos e também aos temas transversais.

A proposta de trabalhar com temas que estabelecem interconexões entre conceitos científicos, cotidiano dos educandos a partir dos temas transversais, valores, atitudes e procedimentos pode favorecer aquilo que Libâneo (2016) chama de direito à semelhança e direito à diferença.

No entanto, nesse ponto, também se deve ter atenção para que o trabalho com os temas não acabe acentuando a desigualdade social, pois a valorização do atendimento a diferenças individuais e culturais não pode obscurecer a realidade das desigualdades sociais. Para Libâneo (2016), em uma política em que o atendimento às diferenças é prioritário, o direito ao conhecimento escolar é colocado em segundo plano, promovendo desigualdade social.

No documento, são apresentadas várias orientações didáticas. Esse é um ponto interessante da proposta curricular para EJA, pois, após selecionar os conhecimentos classificados como importantes, existem inúmeras possibilidades de se desenvolver o trabalho em sala de aula. Na proposta, as orientações aparecem em tópicos e são discutidas e exemplificadas. Há, por exemplo, um tópico de como utilizar o livro didático, trabalhos com projetos, sistematização do conhecimento, uso do computador e da internet, entre outros. Acreditamos que o modo como são apresentadas as orientações didáticas auxiliará o professor a trabalhar com os conteúdos escolhidos diante de uma clientela tão diversificada.

A proposta curricular sugere algumas formas de avaliação que levam em consideração as dificuldades dos educandos da EJA em realizar provas, seja pelas experiências negativas que possivelmente os fizeram abandonar a escola, ou pelos diferentes niveis de aprendizado, que, segundo o documento, é comum em salas da EJA. É sugerida uma avaliação contínua e variada a fim de identificar avanços individuais no aprendizado. Como a proposta apresenta um leque amplo de possibilidades de avaliação e, aparentemente, certa tolerância e respeito à individualidade dos educandos, deve-se ter cuidado nesse ponto, pois tanto a avaliação quanto a facilitação do ensino poderão privar esses educandos do direito à igualdade, conforme pontua Libâneo (2016). Contudo, o documento orienta que pode-se aceitar certa tolerância durante a avaliação em processo, desde que o professor esteja buscando identificar as dificuldades de cada educando para, posteriormente, planejar atividades que os ajudem a superá-las.

Quando se trata de tolerância à diferença, no Quadro 2, são apresentados os resultados da análise do tratamento que o documento confere à questão da diversidade cultural. Nesse quadro, pode-se verificar que a diversidade cultural é discutida principalmente na seção dos temas transversais, no entanto percebe-se uma atenção à diferença na estrutura de escolha dos conteúdos, que estão pautados na realidade dos educandos. A justificativa apresentada 
pelo documento é de que o reconhecimento da diversidade cultural é um direito dos indivíduos e fator de fortalecimento da democracia.

Na seção dos temas transversais tem uma subdivisão: Meio Ambiente; Saúde; Orientação Sexual; Trabalho e Consumo; Pluralidade Cultural e Ética. A seção de pluralidade cultural trata especificamente da questão da diversidade cultural e de sua abordagem dentro do ensino de ciências na EJA. No entanto, a discussão apenas aponta a importância e fornece dicas de como abordar a temática dentro do ensino de ciências na EJA, contudo não embasa a discussão com referenciais teóricos.

Embora o documento discuta pouco a questão da diversidade cultural, notamos que a organização com o objetivo de auxiliar o docente na análise e escolha de conteúdos mais adequados aos educandos pode tornar a escola um projeto aberto e um espaço de comunicação entre grupos sociais diversos, conforme sinalizou Gimeno Sacristán (1995).

Nessa perspectiva, nos parece que o documento busca propiciar o contato do educando com o conhecimento mais poderoso, conforme apontou Young (2013), dando possibilidade de inclusão de outros conteúdos, mais adequados a sua realidade. Pode ser que ao fazer esse movimento, o documento favoreça o acolhimento da diversidade cultural por meio da inclusão de conteúdos, no qual os interesses de diferentes grupos sejam representados.

\section{CONCLUSÕES}

Levando em consideração que o tempo e a heterogeneidade dentro do grupo da EJA são bem característicos, essa abordagem de currículo parece pertinente ao cenário encontrado pelo professor. 0 desenvolvimento do trabalho pedagógico a partir da realidade do educando faz com que o currículo abra espaços para que as diferentes culturas se sintam acolhidas. Contudo, é bom reforçar que, se o respeito à diversidade cultural não for bem discutido pela comunidade escolar, isso poderá acentuar a desigualdade social, uma vez que o foco apenas na diversidade e na formação para a cidadania, em detrimento dos conhecimentos científicos acumulados, poderá reduzir as possibilidades de esses educandos ampliarem seus conhecimentos.

\section{Cultural diversity and the content of science: a tension in the curricular proposal of the EJA}

Abstract: This article is a discussion from an analysis of a curricular proposal for teaching science in EJA, elaborated by the MEC in 2002. It is discussed how the document deals with the tension between science content and attention to diversity in its proposal. That is why we developed a set of questions and put both the questions 
and the answers in one or two frames. In the first frame, we have the presentation of the contents and in the second frame, the treatment given to diversity. We have concluded that the guidelines made by the curricular proposal may help the teacher to choose the most appropriate content to students. We observed the choice of the most relevant content can embrace such diversity. However, the focus only on the diversity of such students and training for citizenship at the expense of the accumulated scientific knowledge can reduce the chances of these students enhance their knowledge further accentuating inequalities.

Keywords: Curricular proposal. Young and Adult Education. Cultural diversity. Science content. Training for citizenship.

\section{REFERÊNCIAS}

BRASIL. Ministério da Educação. Proposta Curricular para a Educação de Jovens e Adultos: Ciências Naturais. Brasilia: Ministério da Educação, v.3, 2002.

FORQUIN, J. C. Escola e cultura: bases sociais e epistemológicas do conhecimento escolar. Porto Alegre: Artmed, 1993.

GIMENO SACRISTÁN, J. Currículo e diversidade. In: SILVA, T. T.; MOREIRA, A. F. B. (Orgs.). Territórios contestados. 0 currículo e novos mapas políticos e culturais. 4. ed. Petrópolis: Vozes, 1995.

HEDEGAARD, M.; CHAIKLIN, S. Radical-local teaching and learning: a culture-historical approach. Aarhus, Denmark: Aarhus University Press, 2005.

LIBÂNEO, J. C. Políticas educacionais no Brasil: desfiguramento da escola e do conhecimento escolar. Cadernos de Pesquisa, São Paulo, v. 46, n. 159, p. 38-62, 2016. Disponivel em: <http:// www.scielo.br/pdf/cp/v46n159/1980-5314-cp-46-159-00038.pdf>. Acesso em: 28 nov. 2016.

NÓVOA, A. Professores: imagens do futuro presente. Lisboa: Educa, 2009.

YOUNG, M. F. D. Superando a crise na teoria do currículo: uma abordagem baseada no conhecimento. Cadernos Cenpec, v. 3, n. 2, p. 226-250, 2013. Disponivel em: <http://cadernos. cenpec.org.br/cadernos/index.php/cadernos/article/view/238/249>. Acesso em: 28 nov. 2016. 